\title{
SECAGEM: UMA REVISÃO
}

\section{DRYING: A REVIEW}

Fernanda Pereira Martins ${ }^{1}$, Juan Canellas Bosch Neto ${ }^{2}$, Alex Júnior Oliveira Silva ${ }^{3}$ e Antonio Marcos de Oliveira Siqueira $^{4}$

${ }^{1}$ Universidade Federal de São João del-Rei, Brasil, E-mail: fernandapmartins@yahoo.com.br, ORCID: https://orcid.org/0000-0002-3884-2292

2 Universidade Federal de São João Del-Rei, Campus Alto Paraopeba, Brasil, E-mail: jboschbr@yahoo.com.br, ORCID: https://orcid.org/0000-0002-2719-7689

3 Universidade Federal de São João del-Rei, Brasil, E-mail: alexjuniorufsj@yahoo.com.br, ORCID: https://orcid.org/0000-0002-1158-8722

4 Universidade Federal de Viçosa, Departamento de Química; Viçosa/MG, Brasil; E-mail: antonio.siqueira@ufv.br; ORCID: https://orcid.org/0000-0001-9334-0394

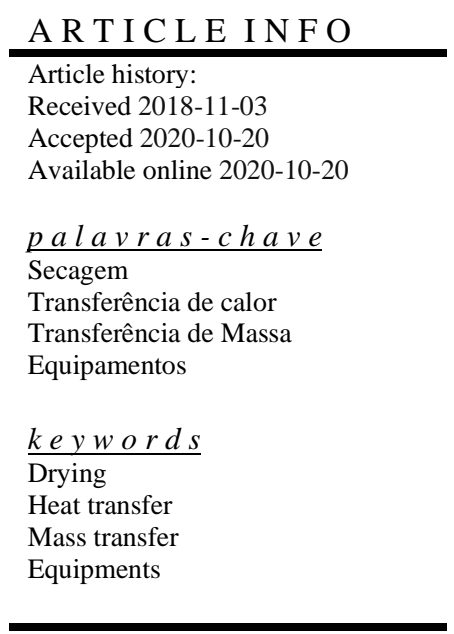

\begin{abstract}
A B S T R A C T
Drying is one of the most used unit operations industrially, with the purpose of eliminating a volatile liquid through evaporation, through the supply of a heat source. Through drying, many products acquire a longer shelf life, in addition to facilitating logistics and marketing. In this article the theoretical foundations of drying were presented, as well as the most used equations and equipment.
\end{abstract}

R E S UM O

A secagem é uma das operações unitárias mais utilizadas industrialmente, tendo como finalidade eliminar um líquido volátil por meio da evaporação, através do fornecimento de uma fonte de calor. Por meio da secagem, muitos produtos adquirem uma vida útil maior, além de facilitar a logística e a comercialização. Neste artigo as fundamentações teóricas da secagem foram apresentadas, bem como as equações e equipamentos mais utilizados. 


\section{Introdução}

Devido ao grande crescimento urbano, há a necessidade da construção de grandes centrais de produção de energia elétrica para suprir a necessidade de tal desenvolvimento, onde se torna fundamental o uso de uma extensa rede de transmissão de energia. A construção de linhas de transporte de energia depende de fatores, como a topografia do terreno, a composição geológica do mesmo afetando o tipo de fundação que será utilizada nas superestruturas (MENEZES, 2015).

A operação unitária de secagem consiste em retirar a quantidade de água de um material, o que ocasiona uma redução na massa do mesmo (MCCABE, et al., 1991). É amplamente utilizada para conservar alimentos, pois os micro-organismos decompositores não crescem na ausência de água. Além disso muitas enzimas que causam o escurecimento enzimático também são desativadas em meios sem água.

São muitas as vantagens da secagem, dentre as quais: a preservação de alimentos, a disponibilidade destes produtos nos períodos de entressafra ou de produção inexistente, a redução de custos de armazenamentos e transporte devido à redução de peso e do volume do produto, a estabilidade dos componentes aromáticos, a proteção contra a degradação enzimática e a economia de energia por não necessitar de refrigeração para conservar o alimento.

Já a secagem realizada de forma inapropriada pode causar alterações indesejáveis de cor e sabor, assim como levar a perda de componentes voláteis (PARK et al., 2006). Geralmente a secagem é a etapa final de um processo e garante que muitos produtos, como sabões em pó e corantes fiquem prontos para o uso (GEANKOPLIS, 2006).

Quando um sólido úmido é submetido a secagem ocorrem simultaneamente dois fenômenos: transferência de massa e transferência de calor. A transferência de massa (umidade) no processo está relacionada com a difusão da água no interior do sólido para a superfície.

A resistência a transferência de massa é representada pelo coeficiente convectivo de massa e de difusão. Já a transferência de calor (energia) ocorre na superfície do sólido, onde a água que ali se encontra se vaporiza. A resistência a transferência de calor na superfície é representada pelo coeficiente convectivo de calor. Muitos mecanismos de transporte são estudados, tais como difusão molecular, capilaridade e difusão líquida (ZOGZAS, 1996).

A secagem requer uma grande quantidade de energia para a operação, portanto ainda são necessários muitos estudos a fim de otimizar o processo e garantir a viabilidade econômica do produto final, estudando os fenômenos de transferência de calor e massa de forma a relacionar o tipo de secador com o material a ser seco.

O objetivo deste artigo é abordar a teoria a respeito da secagem: equações de cálculo, tipos de secadores, eficiência energética e os métodos numéricos aplicáveis. Estes conhecimentos são de grande importância aos discentes das
Engenharias, uma vez que a operação é utilizada na maioria dos processos industriais.

\section{Curvas de Secagem}

O processo de secagem pode ser representado por uma curva que relaciona o Tempo de Secagem (h) versus Teor de Umidade (X). Através dela percebe-se que o teor de umidade apresenta uma variação constante entre os pontos B e C, que representam o período em que a difusão de água no interior do sólido é igual à quantidade de água que se vaporiza na superfície (FOUST et al., 1982). A curva descrita pode ser observada na Figura 1.

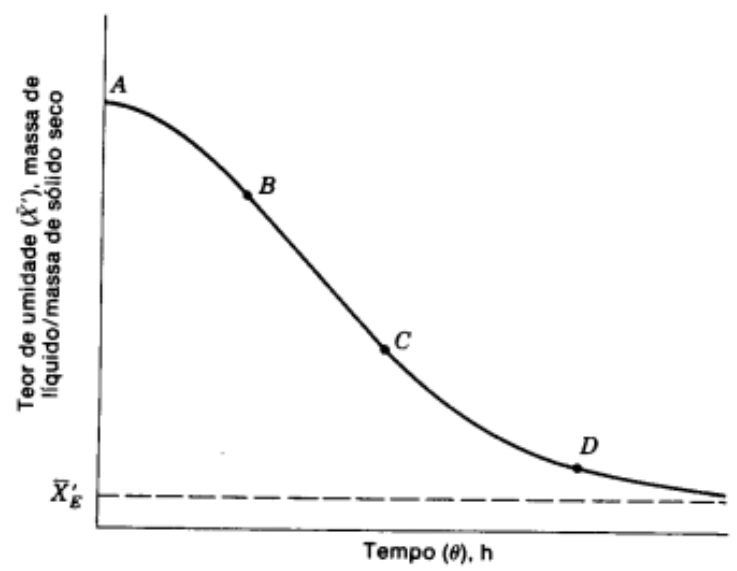

Figura 1: Curva do Tempo de Secagem versus Teor de Umidade presente no sólido.

Fonte: FOUST et al., 1982.

Outra forma de se analisar o processo da secagem é através da curva Teor de Umidade (X) versus Taxa de Secagem. Esta curva representa como a variação da secagem se relaciona com a umidade presente no sólido e está representada na Figura 2.

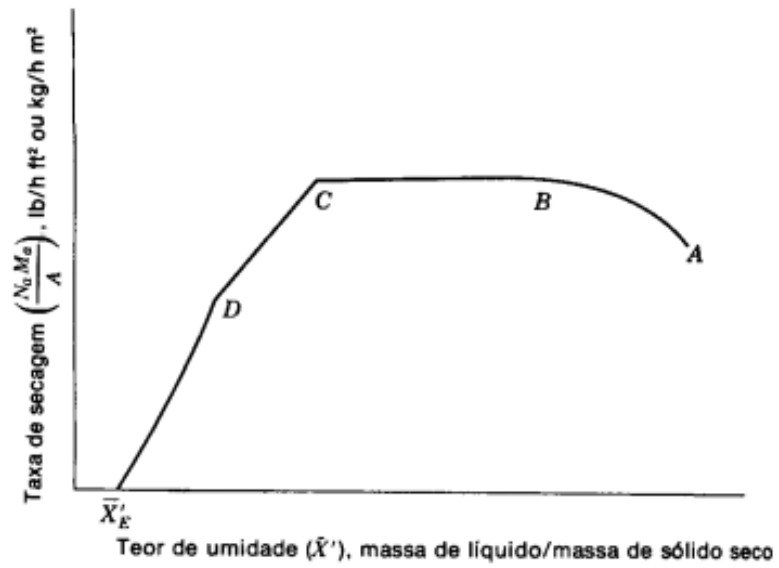

Figura 2: Curva da taxa de secagem versus teor de umidade na secagem.

Fonte: FOUST et al., 1982. 
$\mathrm{O}$ intervalo $\mathrm{AB}$ em ambos os gráficos representa $\mathrm{O}$ primeiro período da secagem, onde a temperatura do sólido bem como a taxa de secagem aumentam até entrar no segundo estágio da secagem, o qual é representado pelo intervalo BC, em que a taxa de secagem é constante. Este estado persiste até que a umidade no interior do sólido seja muito baixa, diminuindo a difusão da água para a superfície do sólido. Para materiais onde o transporte de massa é feito por difusão, que é o caso de sólidos orgânicos fibrosos, este intervalo é curto, dependendo das condições do ar (FOUST et al., 1982).

Uma vez em que as forças resistivas à transferência de massa sejam maiores do que a vaporização da água presente na superfície do sólido, um decréscimo na taxa de secagem é observado, como mostra no intervalo $\mathrm{CD}$ em ambos os gráficos. Como a quantidade de energia necessária para vaporizar a água é menor, o sólido passa a aumentar sua temperatura. A partir do ponto $\mathrm{D}$ o teor de umidade é muito baixo no sólido, sendo que em sua superfície não há uma área de saturação. A secagem prossegue até um limite, representado pelo teor de umidade de equilíbrio (XE), onde a pressão de vapor no sólido é igual à pressão parcial do vapor no ar (FOUST et al., 1982).

$\underline{\text { 2.1 Equações para os cálculos de taxa de secagem e umidade do }}$ sólido

Para analisar um processo experimental de secagem, deve-se construir uma curva de secagem. Para tal, um tratamento dos dados experimentais deve ser feito para serem determinadas as taxas de evaporação (R) e a umidade média do sólido para vários pontos. Desta forma a curva representada pela Figura 1 pode ser encontrada. A umidade do sólido em base seca pode ser encontrada através da Equação 1 (YANNIOTIS, 2007).

$X=\frac{m_{u}-m_{s}}{m_{s}}$

Onde X representa a umidade em base seca do sólido, mu é a massa úmida e ms é a massa seca. Para calcular o valor de umidade em base seca inicial $\left(X_{0}\right)$ e final $\left(X_{f}\right)$ de determinado alimento utiliza-se as equações 2 e 3 (YANNIOTIS, 2007).

$X_{0}=\frac{1-Y_{0}}{Y_{0}}$

$X_{f}=\frac{1-Y_{f}}{Y_{f}}$

A taxa de secagem é calculada utilizando a Equação 4 (YANNIOTIS, 2007).

$\mathrm{R}=-\frac{m_{s}}{\mathrm{~A}} \frac{d X}{d t}$

Onde $\mathrm{R}$ é a taxa de evaporação, $\mathrm{A}$ é a área de troca térmica, ms é a massa de sólido seco, X é a umidade em base seca e t é o intervalo de tempo (YANNIOTIS, 2007).
Ao construir uma curva de secagem, percebe-se dois principais estágios, que são o período de secagem constante, que ocorre a uma taxa de secagem crítica e um período de decaimento que ocorre a taxas de secagem menores que a crítica. É possível estimar o tempo de secagem, tanto para a etapa de secagem constante quanto para a taxa de decaimento tendo-se o valor da taxa crítica de secagem $(\mathrm{Rc})$. Se a secagem se encontra dentro do período de taxa constante, de maneira que tanto X1 como X2 são maiores que Xc, então R é constante e igual à Rc (taxa de secagem crítica). Ao integrar a Equação 2 para o período de taxa constante, temos a Equação 5. Já a integração para o período de decaimento da taxa fornece a Equação 6 (GEANKOPOLIS, 2006).

$$
\begin{aligned}
& t_{c}=\frac{m_{s}}{\mathrm{~A}} \cdot \frac{X_{0}-X_{C}}{R_{c}} \\
& t_{d}=\frac{m_{s}}{\mathrm{~A}} \cdot \frac{X_{1}-X_{E}}{R_{c}} \cdot \ln \frac{X_{c}-X_{E}}{X_{f}-X_{E}}
\end{aligned}
$$

Onde tc é o tempo para o período de secagem constante, ms é a massa de sólido seco, A é a área de secagem, X0 é a umidade em base seca inicial, $X^{c}$ é a umidade crítica em base seca, Rc é a taxa crítica de secagem, td é o tempo de secagem para o período de decaimento, X1 corresponde ao primeiro ponto do período de decaimento, XE é a umidade em base seca de equilíbrio (final da secagem), Xf é a umidade em base seca final desejada para a secagem (YANNIOTIS, 2007).

Assim, o tempo total da secagem é a soma entre os tempos de secagem constante e de decaimento (YANNIOTIS, 2007).

$$
t_{\text {total }}=t_{o}+t_{d}
$$

\section{Tipos de Secadores}

O processo de secagem pode ser executado em batelada, quando o material é inserido no equipamento de secagem e acontece por um certo período de tempo, ou contínuo, onde há uma adição constante de material e o produto seco é removido continuamente, não havendo assim interrupção do processo, a não ser por alguma falha no equipamento. A forma de processamento do produto (batelada ou contínuo) e o método de transferência de calor utilizado (condução ou convecção) diferenciam os tipos de secadores. A seguir são apresentados os principais secadores utilizados em indústrias alimentícias, metalúrgicas, cerâmicas e farmacêuticas.

\subsection{Secador de Bandejas}

Trata-se do tipo de secador mais simples, podendo ter espaço para 10 ou 20 bandejas, onde o material é espalhado em uma espessura de 10 a $100 \mathrm{~mm}$. As bandejas podem ser de fundo telado, no qual o ar passa através do material que está na bandeja ou podem ser de fundo inteiriço em que o ar circula entre o topo de uma bandeja e o fundo da que fica em cima. 
Neste tipo de secador os métodos de secagem utilizados são condução e convecção (FOUST et al., 1982). Uma hélice paralela à bandeja é responsável por recircular o vapor quente, sendo que cerca de 10 a $20 \%$ do ar que passa pela bandeja é fresco e o restante trata-se de ar recirculado, o que permite controlar a umidade do ar no nível desejado e conservar a energia. Também pode ser utilizado o aquecimento elétrico quando o aquecimento não está sendo suficiente. Materiais sólidos granulosos ou sólidos pastosos podem ser secos neste tipo de secador. Um exemplo de secador de bandejas está exposto na Figura 3.

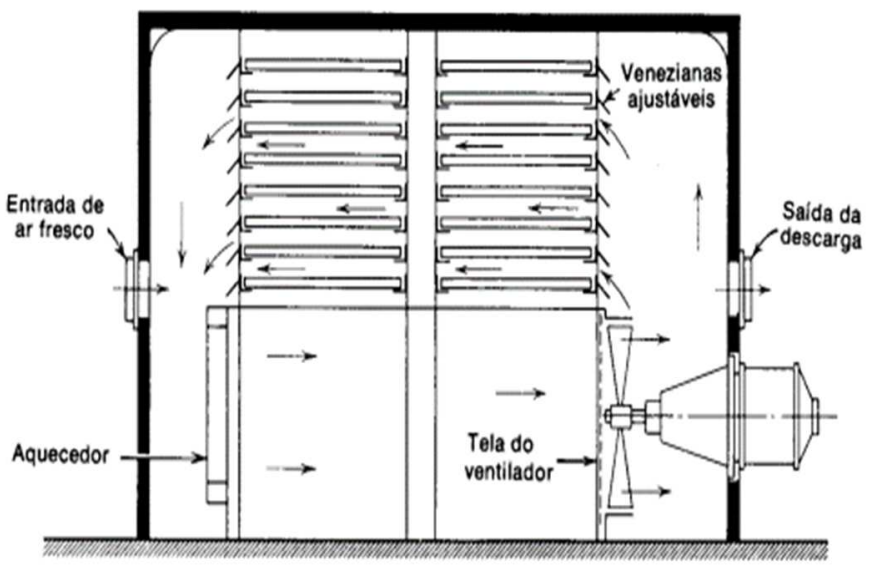

Figura 3: Secador de bandejas.

Fonte: FOUST, 1982, p. 409.

\section{$\underline{3.2}$ Secador de Leito Fluidizado ou Leito de Jorro}

Consiste em um equipamento no qual o material úmido alimentado é seco pelo contato com o ar aquecido que é soprado através do leito, portanto partícula e ar passam a se comportar como um fluido homogêneo. A alimentação que será aquecida entra pelo topo do leito e o produto seco é retirado próximo ao fundo. Os secadores de leito fluidizado podem ser de dois tipos: circular com um leito profundo $(0,5$ a 2,0 m) e retangular com um leito de até $0,2 \mathrm{~m}$ de profundidade. Muitas vezes o último compartimento de alguns secadores retangulares é fluidizado com gás frio para arrefecer os sólidos antes da descarga.

A eficiência na utilização de um leito fluidizado depende em primeiro lugar do conhecimento da velocidade mínima de fluidização, pois abaixo desta o leito não fluidiza e muito acima dela, os sólidos são carregados para fora do leito. O desempenho do processo e a qualidade do produto dependem da fluidodinâmica das partículas no leito (DANTAS, 2013). Os gases efluentes da câmara de secagem, que consistem no gás de combustão, vapor de água e partículas finas, são conduzidos para um ciclone para a recuperação dos sólidos finos. O material arrastado do leito pelo processo de fluidização é recolhido e se junta ao material seco.

O gás natural é o principal insumo e representa o maior custo neste processo. Embora o consumo elétrico seja elevado, uma vez que o ventilador é utilizado para fluidizar o leito, um dos principais atrativos deste sistema é o maior contato superficial entre sólido e fluido, o que favorece a transferência de massa e calor à baixas temperaturas, obtendo uma rápida secagem, sendo extremamente importante para substâncias sensíveis à temperatura.

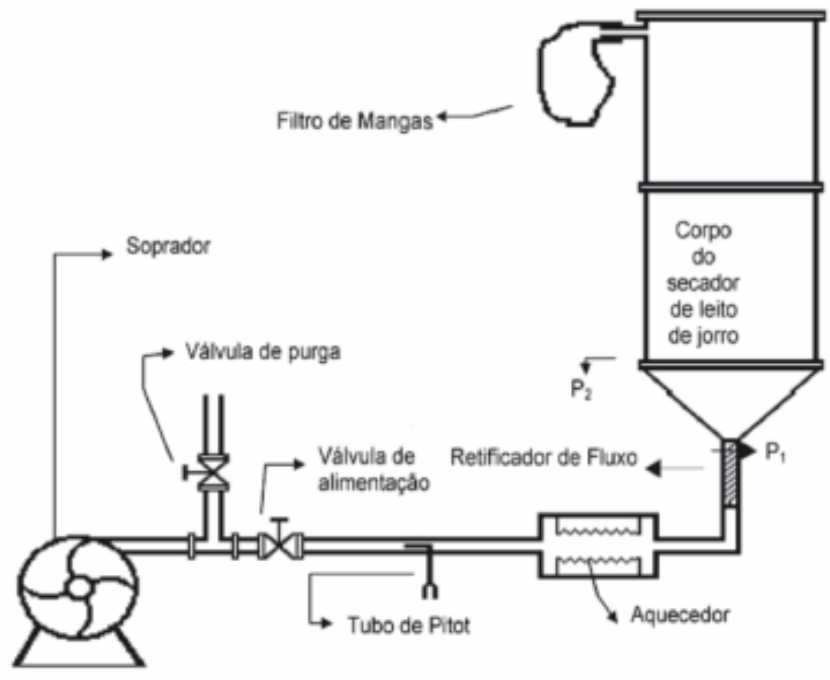

Figura 4: Secador de leito fluidizado.

Fonte: Dias et. al. (2000).

\section{$\underline{3.3 \text { Torres de secagem (Secadores pulverizadores) }}$}

A secagem por pulverização, mais conhecida como "spray dryer", tem como grande diferencial a obtenção de produtos na forma de pó, eliminando etapas posteriores de moagem. Possui pequeno tempo de residência dos produtos na câmara de secagem sendo, portanto, uma alternativa para produtos sensíveis ao calor, como os de origem biológica.

$\mathrm{O}$ equipamento é relativamente grande e pode ser pouco eficiente na utilização da energia. A forma de um secador pulverizador pode variar muito de acordo com o produto a ser seco. O processo consiste basicamente na penetração do ar na câmara de secagem através de um filtro e de um aquecedor. $\mathrm{O}$ ar flui paralelamente com as gotas que se formam no atomizador e que serão secadas posteriormente. À medida que as gotículas atomizadas caem, a umidade é então retirada. As gotículas maiores caem até o fundo da câmara, as gotículas muito finas passam pelo soprador e entram num sistema de lavagem a úmido e as gotículas menores são arrastadas até os ciclones separadores. O sistema de coleta do produto usa na maioria das vezes um ciclone coletor, podendo usar também um filtro de mangas.

O equipamento pode ser pouco eficiente na utilização de energia devido ao seu grande tamanho. Os secadores pulverizadores são utilizados em uma série de aplicações nas indústrias alimentícia e farmacêutica. 


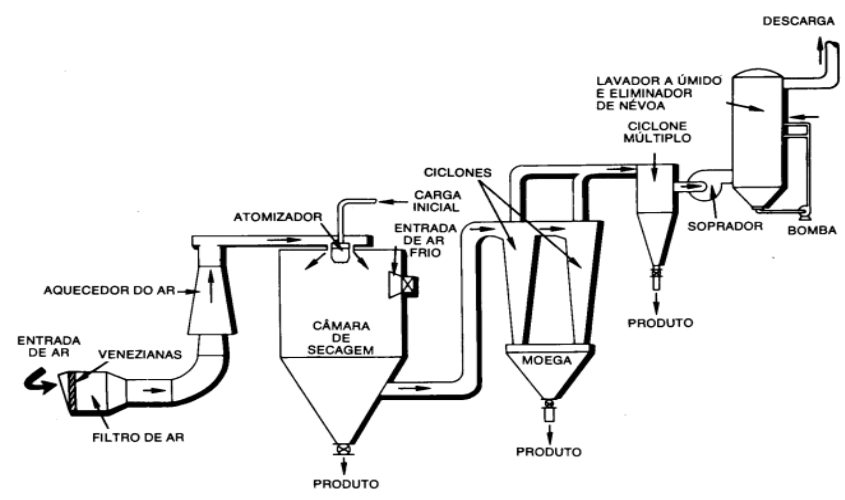

Figura 5: Fluxograma de um sistema de secagem por pulverização.

Fonte: FOUST, 1982, p. 425.

\subsection{Secador de Tambor Rotativo}

Consiste em cilindros horizontais giratórios que são aquecidos internamente por vapor de água. É mais utilizado para secar substâncias orgânicas, pois neste tipo de secador o produto seco não pode ser duro, evitando assim, a danificação da superfície do tambor. Na superfície externa é espalhada a substância a ser seca e à medida que o tambor efetua as rotações, cujas velocidades variam entre 1 e $10 \mathrm{rpm}$, o processo de secagem acontece. A crosta é raspada com uma faca quando a suspensão completa três quartos de uma rotação completa e o produto é obtido na forma de escamas.

Os secadores a tambor possuem diferentes configurações e podem ser alimentados de diferentes formas. Temos os seguintes: secador a tambor duplo, secador a tambor geminado, secador a tambor único com tabuleiro de alimentação e secador a tambor duplo à vácuo. Nos secadores a tambor duplo, a suspensão é colocada entre os dois tambores gigantes, já os secadores a tambores geminados funcionam semelhante aos secadores a tambor duplo, porém giram em direções opostas. Existem dois tipos de alimentação para os secadores a tambor geminado: a primeira consiste na alimentação pelo topo, na qual é mais vantajosa quando o material é granular e facilmente seco, permitindo a formação de um revestimento espesso sobre as superfícies rolantes; a segunda é a alimentação por projeção, na qual a projeção da carga sobre o tambor auxilia a sua aderência às superfícies e forma um revestimento denso.

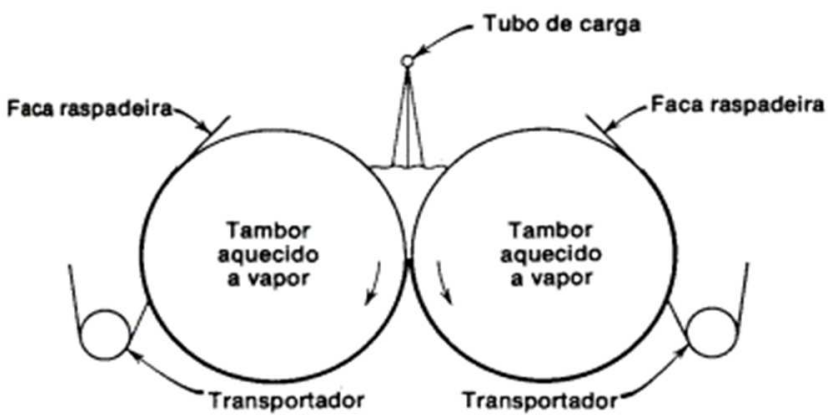

Figura 6: Secador a tambor duplo, mostrando o dispositivo de alimentação, o sentido da rotação dos tambores e o sistema de descarga do produto.

\subsection{Liofilizador}

A secagem por liofilização consiste no congelamento do alimento e posteriormente, sob vácuo ocorre a desidratação, assim a água é eliminada por sublimação para a fase vapor. Este tipo de secagem é muito utilizado nas indústrias alimentícias quando não se deseja perder os nutrientes.

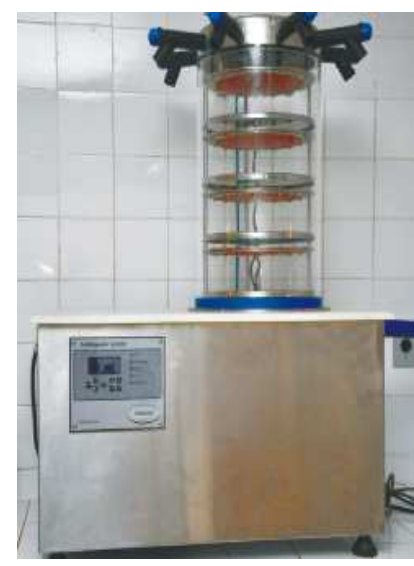

Figura 7: Liofilizador.

Fonte: Princípios de Secagem de Alimentos, EMBRAPA Cerrados (2010).

\subsection{Secador de Túnel}

Composto por um cilindro oco giratório que é levemente inclinado na extremidade, o material flui gradualmente do bocal de alimentação até o bocal de saída, utilizando como meio secante vapor superaquecido ou gases de combustão. Como a superfície exposta do sólido é muito maior, este secador possui uma elevada taxa de secagem, a qual só é vantajosa quando se pode manter o ar não saturado, o que geralmente é obtido pelo acoplamento dos tubos aquecidos a vapor.

A quantidade da carga dos sólidos úmidos é um fator que afeta consideravelmente toda a operação, pois se for muito pequena reduz a taxa de produção e se for muito grande provoca uma ação elevatória irregular, com uma parte dos sólidos rolando no fundo do tambor e podendo ocasionar um produto úmido, o qual não é o objetivo do processo.

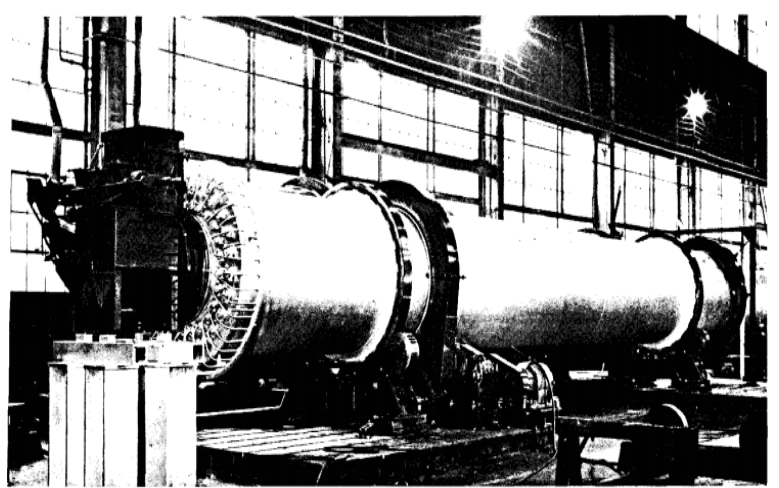

Figura 8: Secador rotatório com tubos de vapor internos.

Fonte: FOUST, 1982, p. 415.

Fonte: FOUST, 1982, p. 423. 


\section{Eficiência energética no processo de secagem}

Por se tratar de um processo caro, torna-se importante a adoção de tecnologias de modo a aumentar a eficiência energética e viabilizar economicamente o valor final do produto. A secagem em excesso consiste em um desperdício de energia, o que pode levar a degradação do produto (ARAÚJO, 2013). Para escolher o melhor tipo de secador para um material é importante levar em consideração parâmetros como custo, qualidade e facilidade de uso (HONORATO, 2006). As características do material a ser seco (granulometria, geometria, densidade, umidade inicial e umidade final desejada) e do equipamento (tipo de ventilador, sistema de aquecimento e combustível utilizado), a quantidade de material alimentado, tempo de residência e as condições ambientais (temperatura e umidade) permitem determinar o tipo de secador que deve ser empregado de forma a viabilizar o processo.

O "spray dryer" tem sido apontado nos últimos anos como o tipo de secador de maior viabilidade econômica, pois alia a elevada taxa de transferência de calor com o baixo tempo de residência, o que evita a degradação e a perda de nutrientes do material (Rajan et., al 2008). Araújo (2013) verificou que os processos de pré-tratamento (moagem, prensagem e mistura) também contribuem para uma significativa redução do teor de umidade inicial da matéria-prima. Portanto, é interessante a utilização destas operações antes da secagem, o que reduz a quantidade de energia requerida nesta etapa. Segundo Fernandes (2005) a eficiência energética da secagem de pastas em leito de jorro é favorecida pelo aumento na vazão e pela diminuição das potências de aquecimento.

\section{Métodos Numéricos Aplicados a Transferência Simultânea de Calor e Massa}

Um modelo numérico utiliza equações matemáticas que descrevam o processo e tem como objetivo se relacionar aos dados experimentais. No caso da secagem o modelo descreve a variação da taxa de umidade ao longo do tempo. Os modelos podem ser divididos em três tipos: empíricos e semi-empíricos, difusivos e aqueles baseados na termodinâmica dos processos irreversíveis (SILVA, 2010). Dentre eles, os mais encontrados na literatura são os modelos difusivos e os termodinâmicos.

Os modelos empíricos correlacionam diretamente o teor de umidade e o tempo de secagem, já os semi-empíricos assumem que a diferença entre o teor de umidade e seu respectivo teor de umidade no equilíbrio é proporcional a taxa de secagem. Os modelos baseados no fenômeno da difusão descrevem simultaneamente as taxas de transferência de massa e calor, levando em consideração as resistências aos fluxos mássico e de energia, respectivamente. No fenômeno da difusão atuam a diferença na pressão de vapor e no teor de umidade. Os modelos baseados na termodinâmica dos processos irreversíveis descrevem o equilíbrio termodinâmico no interior do material.

A $1^{\circ}$ Lei de Fick da difusão descreve a taxa de transferência de massa para o estado estacionário conforme Equação 8 (KONDO, 2014).

$$
\frac{d m}{d t}=-\frac{D d m}{d x}
$$

Onde $\frac{d m}{d t}$ é a taxa de transferência de massa (umidade) por tempo (kg/m2.s), $D$ é o coeficiente de difusão (kg/m.s.\%) e $\frac{D m}{d x}$ é o gradiente de umidade no material $(\% / \mathrm{m})$.

A $2^{\circ}$ Lei de Fick da difusão descreve a taxa de transferência de massa para o estado não-estacionário conforme Equação 9 (KONDO, 2014).

$\frac{\partial u}{\partial t}=\nabla \cdot\left(D_{e f} \nabla u\right)$

Onde $u$ é o teor de umidade ( $\mathrm{kg} \mathrm{H} 2 \mathrm{O} / \mathrm{kg}$ sólido seco), $D_{e f}$ é a difusividade efetiva de massa (m2/s) e $t$ é o tempo (s).

Segundo WELT (2007) ao utilizar a Lei de Fick deve-se fazer o uso de algumas hipóteses simplificadoras, tais como geometria do material (plana, cilíndrica ou esférica), direções da transferência (unidimensional, bidimensional), geração ou não de massa durante o processo, presença de resistências externas e da difusividade efetiva, além das respectivas condições de contorno.

Os fenômenos de transporte de energia e umidade são estudados por alguns autores na literatura, dentre eles Luikov (1966), que obteve um sistema de equações diferenciais ao relacionar três varáveis dependentes: pressão, temperatura e teor de umidade total e demonstrou que o fluxo de massa pode ser escrito em função do gradiente do teor de umidade e da temperatura do meio. Através dos conhecimentos em termodinâmica dos processos irreversíveis, Luikov determinou os balanços de massa e de energia e desprezou os efeitos gravitacionais, reacionais e de variações geométricas da matriz porosa (SILVA, 2010). De acordo com Luikov quando há uma diferença de concentração ou de temperatura entre dois pontos, o sistema tende a alcançar o equilíbrio por meio de um fluxo de um ponto para o outro.

O sistema de equações de um modelo pode ser resolvido por alguns métodos numéricos de discretização, os quais consistem na aproximação destas equações por um sistema de equações algébricas em pontos discretos no espaço e no tempo. As equações do modelo podem ser escritas em coordenadas cilíndricas, esféricas ou cartesianas. A medida que crescem o número de variáveis, são necessárias ferramentas computacionais para facilitar a resolução destes modelos matemáticos. A representação geométrica do domínio (malha numérica) é a posição discreta na qual as variáveis são calculadas (FERZIGER e PERIC, 1997).

Algumas aproximações finitas são utilizadas no processo de discretização, tais como: método dos elementos finitos, método dos volumes finitos e método das diferenças finitas. $\mathrm{O}$ método dos elementos finitos é usado tanto para resolver problemas contínuos quanto discretos. Neste caso as equações são multiplicadas por uma função peso antes de serem integradas em todo o domínio. O método dos volumes finitos compreende a integração de equações (diferenciais, ordinárias ou parciais) da conservação, as quais são aplicadas aos volumes de controle. O método das diferenças finitas é o mais fácil de ser utilizado para geometrias simples, porém é restrito a este tipo de geometria. Segundo FERZIGER e PERIC (1997), neste método 
as aproximações das derivadas são obtidas através da expansão em série de Taylor ou pela aproximação polinomial.

\section{Considerações Finais}

A secagem é uma das operações unitárias mais utilizadas na indústria, sendo também de custo muito elevado. Neste sentido torna-se necessário ao graduando e futuro profissional competente da área, um sólido conhecimento teórico para melhor eficiência no processo. O presente trabalho apresenta os fundamentos principais a respeito da secagem. Recomenda-se em estudos futuros a aplicação dos conceitos e equações aqui descritos para maior compreensão dos mesmos, além da comparação em contextos variáveis.

\section{Agradecimentos}

Os autores agradecem o apoio por parte do Departamento de Engenharia Química (DEQUI) da Universidade Federal de São João del Rei (UFSJ) e da Universidade Federal de Viçosa (UFV). O presente trabalho foi realizado com apoio da Coordenação de Aperfeiçoamento de Pessoal de Nível Superior - Brasil (CAPES) - Código de Financiamento 001 e da Fundação de Amparo à Pesquisa do Estado de Minas Gerais (FAPEMIG).

\section{Referências}

ARAÚJO, C. D. M. De. Eficiência energética em sistemas de secagem. Estudo de caso: Produção de farinha de cascas de banana. 2013. 69 f. Dissertação (Mestrado em Engenharia de Energia). Universidade Federal de Itajubá - Programa de Pós Graduação em Engenharia de Energia. Itajubá, MG.

DANTAS, T. N. P. Avaliação de dados de secagem de suspensões de polpas de frutas em leito de jorro com alimentação intermitente. 2013. 109 f. Dissertação (Mestrado em Engenharia Química). Universidade Federal do Rio Grande do Norte - Programa de Pós Graduação em Engenharia Química. Natal, RN.

DIAS, C. M; MARQUES, W. M; BORGES, S. V; MANCINI, M. C. Efeito da Secagem em leito de jorro bidimensional sobre as propriedades físicas e tecnológicas do feijão preto (Phaseolus vulgaris, L.). Ciência e Tecnologia de Alimentos, v. 20, n. 3, p. 76-79, 2000.

EMBRAPA - Empresa Brasileira de Pesquisa Agropecuária. Princípios de Secagem de Alimentos. 1.ed. Planaltina: Embrapa Cerrados, 2010.

FERNANDES, C. F. Análise da Eficiência energética da secagem de pastas em leito de jorro. 2005. $96 \mathrm{f}$. Dissertação (Mestrado em Engenharia Química). Universidade Federal de São Carlos - Programa de Pós Graduação em Engenharia Química. São Paulo, São
Carlos.

FERZIGER, J. H.; PERIC, M. Computational Methods for Fluid Dynamics. Springer-Verlag Berlin Heidelberg. New York, 1997.

FOUST, A. S.; WENZEL, L. A.; CLUMP, C. W.; MAUS, L.; ANDERSEN, L. B. Princípios das operações unitárias. 2a ed. Rio de Janeiro: LTC, 1982. 670 p.

GEANKOPLIS, C. J., Transport Processes and Unit Operations. 3a ed. Prentice-Hall International, Inc., 2006. 921 p.

HONORATO, G. C. Concepção de um secador rotatório para secagem do cefalotórax do camarão. 2006. 185 f. Tese (Doutorado em Engenharia Química). Universidade Federal do Rio Grande do Norte - Programa de Pós Graduação em Engenharia Química. Natal, RN.

KONDO, M. Y. Simulação numérica do processo de secagem em madeiras. 2014. 99 f. Dissertação (Mestrado em Engenharia Mecânica). Universidade Estadual Paulista Programa de Pós Graduação em Engenharia Mecânica. Guaratinguetá, SP.

MCCABE, W. SMITH, J.; HARRIOT, P. Unit operations of chemical engineering. 5a ed. New York: McGraw-Hill, Inc., $1991.1130 \mathrm{p}$.

PARK, K. J.; ANTONIO, G. C.; OLIVEIRA, R. A.; PARK, K. J. B. Seleção de processos e equipamentos de secagem. CONBEA, Universidade Estadual de Campinas, 2006.

RAJAN, K. S., DHASANDHAN, K., SRIVASTAVA, S. N., PITCHUMANI, B. Studies on gas - solid heat transfer during pneumatic conveying. International Journal of Heat ans Mass Transfer 51 (2008) 2801 - 2813.

SILVA, C. K. F. da. Estimação de parâmetros de secagem de alimentos - formulação de Luikov e uso da Transformada Integral Generalizada. 2010. 127 f. Tese (Doutorado em Engenharia Mecânica). Universidade Federal da Paraíba - Programa de Pós Graduação em Engenharia Mecânica. João Pessoa, PB.

WELTY, J. R.; WICKS, C. E.; WILSON, R. E.; RORRER, G. L. Wilson Fundamentals of Momentum, Heat, and Mass Transfer. 5th Edition. United States of America, 2007.

YANNIOTIS, S. Solving Problems in Food Engineering. Springer, New York, NY, 2008.

ZOGZAS, N. P., MAROULIS, Z. B. Effective Moisture Diffusivity Estimation from Drying Data. A Comparison Between Various Methods of Analysis, Drying Technology: An International Journal, 14:7-8 (1996) $1543-1573$. 